\title{
Clinical Usefulness of Schedule for Oral-Motor Assessment (SOMA) in Children with Dysphagia
}

\author{
Moon Ju Ko, M.D., Min Jae Kang, M.D., Kil Jun Ko, M.D., \\ Young Ok Ki, M.S., Hyun Jung Chang, M.D. ${ }^{1}$, Jeong-Yi Kwon, M.D.
}

Department of Physical and Rehabilitation Medicine, Samsung Medical Center, Sungkyunkwan University School of Medicine, Seoul 135-710, ' Samsung Changwon Hospital, Sungkyunkwan University School of Medicine, Changwon 630-723, Korea

Objective To investigate the clinical usefulness of the Schedule for Oral-Motor Assessment (SOMA) in children with dysphagia by comparing findings of SOMA with those of the videofluoroscopic swallowing study (VFSS).

Method Both SOMA and VFSS were performed in 33 children with dysphagia (21 boys and 12 girls; mean age $17.3 \pm 12.1$ months) who were referred for oropharyngeal evaluation. Ratings of oral-motor functions indicated by SOMA were based upon the cutting score of each specific texture of food (puree, semi-solids, solids, cracker, liquid-bottle, and liquid-cup). Abnormalities of either the oral phase, or the pharyngeal phase as indicated by VFSS were assessed by a physician and a speech-language pathologist.

Results There was significant consistency between the findings of SOMA and the oral phase evaluation by VFSS (Kappa $=0.419, \mathrm{p}=0.023$ ). SOMA reached $87.5 \%$ sensitivity, $66.6 \%$ specificity, and $95.4 \%$ positive predictive value when compared with the oral phase of the VFSS. We were able to evaluate oral-motor function by using SOMA in 6 children who were unable to complete the oral phase evaluation by VFSS, due to fear and crying during the study. The findings of SOMA failed to show any consistency with the pharyngeal phase evaluation by VFSS (Kappa $=-0.105$, $\mathrm{p}=0.509$ ).

Conclusion These results suggest that SOMA is a reliable method for evaluation of oral-motor function in children with dysphagia. In particular, SOMA is recommended for children that were unable to complete the oral phase evaluation by VFSS due to poor cooperation.

Key Words Dysphagia, Oral-motor dysfunction, Schedule for Oral-Motor Assessment (SOMA), Videofluoroscopic swallowing study (VFSS)

Received August 23, 2010; Accepted May 17, 2011

Corresponding author: Jeong-Yi Kwon

Department of Physical and Rehabilitation Medicine, Samsung Medical Center, Sungkyunkwan University School of Medicine, 50, Irwon-dong, Gangnam-gu, Seoul 135-710, Korea

Tel: +82-2-3410-2818, Fax: +82-2-3410-0052, E-mail: jeongyi.kwon@ samsung.com

(c) This is an open-access article distributed under the terms of the Creative Commons Attribution Non-Commercial License (http://creativecommons.org/ licenses/by-nc/3.0) which permits unrestricted noncommercial use, distribution, and reproduction in any medium, provided the original work is properly cited. Copyright $\odot 2011$ by Korean Academy of Rehabilitation Medicine

\section{INTRODUCTION}

The movement of food in the oral cavity towards the pharynx differs depending on the type of food (liquid or solid). ${ }^{1}$ For children with dysphagia, abnormalities in the pharyngeal phase often accompany oral-motor dysfunction. Reilly et al. ${ }^{2}$ reported that over $90 \%$ of children with cerebral palsy have oral-motor dysfunction 
and $38 \%$ of them have swallowing problems. Rogers et al. ${ }^{3}$ conducted a videofluoroscopic swallowing study (VFSS) on 90 children with cerebral palsy who complained of difficulty in swallowing. Their results showed that $98 \%$ of these children displayed abnormalities in the oral phase, 99\% showed abnormalities in the pharyngeal phase, and $38 \%$ showed evidence of food aspiration. Oral-motor dysfunction is considered less severe than aspiration or penetration, and is often overlooked clinically. However, it is possible that oral-motor dysfunction may cause aspiration during swallowing, which may cause failure to thrive. ${ }^{4,5}$

In order to provide proper treatment for each of the various causes of dysphagia, a process for evaluating abnormalities during the entire process of swallowing (that is, the assessment of oral, pharyngeal, and esophageal function) is required. ${ }^{5}$ VFSS is the most widely used diagnostic method for dysphagia in the clinical setting. ${ }^{6}$ However, when VFSS is conducted in children, there are many limitations, especially during the oral phase of the assessment. Due to the use of various devices such as the fluoroscope, and the nature of the testing environment, children can experience fear when being evaluated by VFSS, which causes them to cry and resist the procedure. For children who resist strongly or do not stop crying, the test can be continued by forcibly injecting food, and in such cases, evaluation of the oral phase is problematic. Furthermore, in order to reduce the duration of exposure to radiation, the testing time must be minimized, and in the case of infants, the test should be completed within 60-90 seconds. Moreover, it is recommended that total radiation exposure during testing should not exceed a maximum of 2 minutes. ${ }^{7}$ Because the test should be completed within 1-2 minutes, it is usually difficult to obtain an accurate observation of the oral phase. Furthermore, since barium contrast is mixed into the food for the purpose of testing, it is different from the food typically consumed by the children, and may thus affect the results of the oral phase. The Schedule for Oral Motor Assessment (SOMA) is an assessment tool developed by Reilly et al. ${ }^{8}$ for the objective assessment of oral motor function in infants, with a proven reliability and validity based on previous studies. ${ }^{8,9}$ However, studies using SOMA for clinical assessment of oral-motor dysfunction have not been performed in Korean patient populations. There have been some cases where pharyngeal and oral abnormalities were investigated using a VFSS in Korean children, ${ }^{10-12}$ but no studies have used SOMA for the diagnosis of oral-motor dysfunction.

This study was designed to assess the clinical usefulness of SOMA for the evaluation of oral phase in children that were requested to undergo VFSS to evaluate dysphagia.

\section{MATERIALS AND METHODS}

\section{Subjects}

From June 2009 to June 2010, 33 children between the ages of 6 and 48 months that were referred for a VFSS due to dysphagia were selected as subjects for the retrospective study. Children who were feeding via nasogastric tubes at the time of testing were excluded from the study due to the risk of aspiration. The average age of the subjects at the time of the test was $17.3 \pm$ 12.1 months (range: 6-48 months). The patient sample consisted of 21 boys and 12 girls.

\section{Methods}

VFSS: The VFSS was conducted by modifying Logemann's protocol, ${ }^{6}$ and was performed in a fluoroscopy laboratory by an experienced speech-language pathologist and a physiatrist. Subjects were placed in a sitting position, and swallowing was recorded from the lateral and anteroposterior view using radioactive fluoroscopic equipment (Shimavision 3200 HG, Shimadzu, Kyoto, Japan). To improve cooperation by the children, the test was conducted with the assistance of the main caregiver. In situations involving children who were only fed milk, liquid barium (Barium sulfate; Solotop sol 140, Tae Joon Pharmaceutical) was mixed with the milk and then transferred to a bottle to be given to the children for testing. For children who received baby food, a meal including milk, ground apple, and porridge was given (in that order) in conjunction with cookies and milk. Liquid barium was mixed with the food to permit the observation of a food bolus for fluoroscopy.

The VFSS was recorded on video and the recording was interpreted by a speech-language pathologist and a physiatrist. The closing of the lips, food bolus formation, oral residues, and passing time for the oral phase were observed. If any abnormal findings were not observed in all categories, the result was classified 
as normal for the oral phase. Otherwise, the result was classified as abnormal. For the pharyngeal phase, the swallowing reflex, laryngeal elevation and closing of epiglottis, the presence of residues in the epiglottic vallecula and pyriform sinus, opening of the upper esophageal sphincter, and the passing time in the pharynx were assessed. The degree of aspiration was divided into supraglottic penetration and aspiration. Supraglottic penetration referred to when the contrast media passed on top of the vocal folds, but not below the vocal folds. Aspiration was defined as the passing of the contrast media below the vocal folds. When supraglottic penetration or aspiration was observed, it was classified as abnormal for the pharyngeal phase. Furthermore, if other mild pharyngeal abnormalities or additional abnormal findings were not observed, the result was classified as normal.

SOMA: SOMA was conducted by a well-trained speechlanguage pathologist who was separate from the therapist who conducted the VFSS. The test was implemented in the presence of the child's main caregiver. The child was seated in a comfortable position, and the test was administered and scored according to the SOMA manual created by Reilly et al. ${ }^{8}$ The entire assessment lasted approximately 20 minutes per child. The test was conducted for 5 types of food (puree, semi-solids, solids, cracker, liquid-bottle, and liquid-cup). However, depending on the age and preference of the child, if a food type was determined to be unfit for consumption, the test was conducted using the remaining types of food. For the assessment category specified for each tested diet, the tester observed the given food category and assessed it as either "yes" or "no". Based on the criteria of the specified cutting score for each test diet, the abnormality score that was given determined the level of abnormal oral-motor function. When the score was less than the cutting score, test results were determined to be normal (Appendix 1-6). For all the test diets in which the assessment was done, the cases which showed normal oral-motor function with less than the cutting score were classified as normal by SOMA. Other cases with abnormalities above the cutting score in one test diet, were classified as abnormal by SOMA.

\section{Statistical analysis}

SPSS 14.0 version for Windows (Chicago, USA) was used for statistical analysis. Statistical significance was defined as a p-value of less than 0.05 . The consistency between the findings of SOMA and the oral phase of the VFSS was determined using Kappa value analysis.

\section{RESULTS}

Clinical diagnoses for the children who were included as subjects in this study included 4 diagnoses of cerebral palsy (13\%), 5 with other brain lesions (15\%), 5 with epilepsy (15\%), 2 with congenital heart diseases (6\%), 2 with broncho-pulmonary dysplasia (6\%), 5 with gastroesophageal reflux and gastrointestinal motility disorders (15\%), 3 with developmental delay (9\%), 2 with failure to thrive (6\%), 2 with chromosomal anomalies (6\%), and 3 with other conditions (9\%) (Table 1).

The findings of SOMA were reasonably consistent with those of the oral phase of the VFSS (Kappa $=0.419$, $\mathrm{p}=0.023$ ). In the case of the VFSS results, excluding the 6 children who were not able to complete the oral phase evaluation due to fear and crying, out of a total of 27 children, 24 (88.8\%) were found to have abnormalities in the oral phase. Among those with abnormalities, 3 $(12.5 \%)$ were classifed as normal by SOMA (Table 2). Of the total of 33 children with SOMA data, 26 (78.7\%) showed abnormal oral-motor function. Again, excluding those children who were not able to complete the evaluation on the oral phase in the VFSS, 21 out of 22

Table 1. Clinical Diagnosis of the Children Enrolled in This Study

\begin{tabular}{lc}
\hline \multicolumn{1}{c}{ Clinical diagnosis } & Number of patients (\%) \\
\hline Cerebral palsy & $4(13)$ \\
Other brain lesions & $5(15)$ \\
Epilepsy & $5(15)$ \\
Congenital heart diseases & $2(6)$ \\
BPD & $2(6)$ \\
GERD, GI motility disorders & $5(15)$ \\
Developmental delay & $3(9)$ \\
FTT & $2(6)$ \\
Chromosomal anomaly & $2(6)$ \\
Others & $3(9)$ \\
Total & $33(100)$ \\
\hline
\end{tabular}

BPD: Broncho-pulmonary dysplasia, GERD: Gastroesophageal reflux disease, GI: Gastrointestinal, FTT: Failure to thrive 
Table 2. Comparison between SOMA and VFSS Oral Phase

\begin{tabular}{lcc}
\hline & \multicolumn{2}{c}{ SOMA } \\
\cline { 2 - 3 } & Normal & Abnormal \\
\hline VFSS oral phase & & \\
Normal & 2 & 1 \\
Abnormal & 3 & 21 \\
\hline
\end{tabular}

SOMA: Schedule for oral-motor assessment, VFSS: Videofluoroscopic swallowing study

Kappa $=0.419, \mathrm{p}=0.023$, sensitivity: $87.5 \%$, specificity: $66.6 \%$, positive predictive value: $95.4 \%$, negative predictive value: $40.0 \%$

Table 3. Comparison between SOMA and VFSS Pharyngeal Phase

\begin{tabular}{lcc}
\hline & \multicolumn{2}{c}{ SOMA } \\
\cline { 2 - 3 } & Normal & Abnormal \\
\hline VFSS Pharyngeal Phase & & \\
Normal & 2 & 11 \\
Abnormal & 5 & 15 \\
\hline
\end{tabular}

SOMA: Schedule for oral-motor assessment, VFSS: Videofluoroscopic swallowing study

Kappa $=-0.105, \mathrm{p}=0.509$

children (95.4\%) had both abnormal SOMA findings and abnormal findings in the oral phase in the VFSS.

In the case of those 6 children who were not able to complete the assessment of the oral phase of the VFSS, all oral-motor functions assessments were conducted successfully by SOMA. Four of these children were classified as abnormal by SOMA, and 2 were classified as normal. No statistical consistency was found between the findings of SOMA and those of the pharyngeal phase of the VFSS (Kappa $=-0.105, \mathrm{p}=0.509$ ) (Table 3).

Compared with VFSS, SOMA was determined to have $87.5 \%$ sensitivity, $66.6 \%$ specificity, $95.4 \%$ positive predictive value, and $40.0 \%$ negative predictive value in the assessment of oral-motor dysfunction.

\section{DISCUSSION}

The VFSS has been widely used as the standard test to diagnose dysphagia, and is divided into oral, pharyngeal, and esopharyngeal phases for observation by the tester. The presence of aspiration can be directly confirmed, and anatomical and functional problems in the oral and pharyngeal phase can be diagnosed. ${ }^{13}$ However, the VFSS uses a fluoroscopic device, and due to the usually unfamiliar testing environment, it can instigate fear and discomfort in children. In many cases, the children are not able to cooperate during the test, and the test is frequently disrupted by crying or resistance. In such cases, the observation of the oral phase may be limited. Moreover, since barium is mixed into the test food, children may resist ingesting food, which is perceived to be different from their normal diet, and this may have considerable effects on the results of the oral phase evaluation. Therefore, such factors may cause the diagnosis of abnormalities in the oral phase of the VFSS to be inaccurate and the evaluation to be difficult in some cases.

Various assessment tools have been developed to evaluate oral-motor function in the clinical setting. SOMA is an assessment tool designed by Reilly et al., for the objective evluation of oral-motor functions in children, with proven reliability and validity in infants aged 8-24 months. ${ }^{8,9}$ For the 5 types of test diet, based on the cutting score after assessment in each category, subjects are classified into normal or abnormal oralmotor function groups. The Clinical Feeding Evaluation of Infants method devised by Wolf and Glass ${ }^{14}$ is an oralmotor assessment tool for infants who are primarily breast- or bottle-fed. The Oral-Motor Feeding Rating Scale, devised by Jelm ${ }^{15}$ can be divided into 6 grades, with scores ranging from 0 to 5 in each of the assessment categories, and can be used for patients ranging in age from 1 year to adulthood. However, the drawback of this diagnostic tool is that the information used to interpret results is lacking. The Exeter Dysphagia Assessment Technique (EDTA), devised by Selley et al. ${ }^{16}$ can be used for subjects ranging from 2 years of age to adults, and is used to assess oral and pharyngeal abnormalities and breathing patterns during the process of swallowing a liquid. The Multidisciplinary Feeding Profile, designed by Kenny et al. ${ }^{17}$, was developed for use in children aged $6-18$, and is an assessment tool that is used mainly for children with severe feeding disorders, although not much information is provided on how to interpret results. The Developmental Pre-feeding Checklist, designed by Morris and $\mathrm{Klein}^{18}$ is an evaluation tool for oral function mainly in infants aged 0-24 months, but the assessment catogories are numerous and the interpretation of results 
can be difficult. The Neonatal Oral-Motor Assessment Scale (NOMAS), devised by Braun and Palmer ${ }^{19}$ is a tool with proven reliability and validity for the assessment of oral function in infants who bottle feed, and based on the scores generated by this test, subjects can be categorized into normal and abnormal groups. In the present study, the subjects mainly consisted of infants between the ages of 8 and 24 months. Our choice of diagnostic instruments (SOMA) has made it possible to include an assessment of various textures of food, and information on how to interpret the results is provided. Furthermore, SOMA has a proven track record of reliability and validity.

In this study, the findings from the SOMA and the VFSS showed a reasonable consistency in revealing abnormalities (Kappa $=0.419, \mathrm{p}=0.023$ ). Compared with the VFSS, SOMA displayed $87.5 \%$ sensitivity, $66.6 \%$ specificity, $95.4 \%$ positive predictive value, and $40.0 \%$ negative predictive value for the diagnosis of oral-motor dysfunction. In this particular study, 6 out of 33 children were not able to complete their oral phase evaluation by VFSS due to resistance such as crying. SOMA allowed the successful evaluation of oral-motor function for these children. Moreover, 3 out of 24 subjects (12.5\%) with abnormalities observed in the oral phase of the VFSS showed normal oral-motor function in the SOMA. It is thought that children with normal oral-motor function were found to have abnormal findings due to their resistance during the VFSS. Based on such results, when evaluating oral-motor function in children whose cooperation cannot be obtained for the VFSS, it is safe to say that SOMA can replace VFSS as a useful diagnostic tool. However, it would be difficult to use SOMA to accurately evaluate the the presence of abnormalities in the pharyngeal phase (such as aspiration), and thus, for children suspected of dysphagia, both SOMA and VFSS can be conducted for a more accurate diagnosis in the oral and pharyngeal phases.

SOMA is a scale with proven validity for the evaluation of oral-motor function in children between the ages of 8 months and 24 months, ${ }^{8,9}$ and in this study, 25 out of 33 children were aged 8-24 months at the time of testing. The remaining 8 children deviated from this age group, which presents the possibility of error with the interpretation of SOMA results in these children. Furthermore, the number of testing categories assessed for the 5 types of test diets used for SOMA varies in a significant number of children depending on the age and preference of children, presenting a limitation in the sense that the severity of the deterioration in oralmotor function may not be correctly assessed. Despite such limitations, this study has clinical significance in being the first study to compare the VFSS, which is currently widely used as the standard assessment tool for dysphagia, and SOMA, which is a clinical scale of oralmotor function, and proves that these two assessment tools can be used complementarily.

\section{CONCLUSION}

The findings of SOMA were consistent with those of the oral phase of VFSS conducted in children who had been referred for VFSS for dysphagia. Children who were not able to complete the evaluation of the oral phase of the VFSS due to poor cooperation could be assessed for oralmotor function using SOMA. Thus, it was determined that for children with dysphagia, SOMA is a useful diagnostic tool in evaluating oral-motor dysfunction, and when used complementarily with the VFSS, dysphagia can be more comprehensively assessed.

\section{REFERENCES}

1. Matsuo K, Palmer JB. Anatomy and physiology of feeding and swallowing: normal and abnormal. Phys Med Rehabil Clin N Am 2008; 19: 691-707

2. Reilly S, Skuse D, Poblete X. Prevalence of feeding problems and oral motor dysfunction in children with cerebral palsy: a community survey. J Pediatr 1996; 129: 877-882

3. Rogers B, Arvedson J, Buck G, Smart P, Msall M. Characteristics of dysphagia in children with cerebral palsy. Dysphagia 1994; 9: 69-73

4. Gisel EG, Patrick J. Identification of children with cerebral palsy unable to maintain a normal nutritional state. Lancet 1988; 1: 283-286

5. Logemann JA. Swallowing physiology and pathophysiology. Otolaryngol Clin North Am 1988; 21: 613623

6. Logemann JA. Evaluation and treatment of swallowing disorders, 2nd ed, San Diego, College Hill Press, 1998, 168-180

7. Arvedson JC, Brodsky L. Pediatric swallowing and 
feeding: assessment and management, 2nd ed, San Diego, Publishing group inc, 1993, 360-361

8. Reilly S, Skuse D, Mathisen B, Wolke D. The objective rating of oral-motor functions during feeding. Dysphagia 1995; 10: 177-191

9. Skuse D, Stevenson J, Reilly S, Mathisen B. Schedule for oral-motor assessment (SOMA): methods of validation. Dysphagia 1995; 10: 192-202

10. Kim TU, Park WB, Byun SH, Lee MJ, Lee SJ. Videofluoroscopic findings in infants with aspiration symptom. J Korean Acad Rehab Med 2009; 33: 348-352

11. Jung HY, Kim SA, Lee SH, Kim SJ. Characteristics of dysphagia in children with cerebral palsy via videofluoroscopy. J Korean Acad Rehab Med 2000; 24: 671-677

12. Kim HS, Choe JJ. Characteristics of swallowing disorder in pediatric patients with central nervous system disorders: comparing to central nervous system intact patients with gastro-intestinal disorders. J Korean Acad Rehab Med 1998; 22: 506-515

13. Mirrett PL, Riski JE, Glascott J, Johnson V. Videofluoroscopic assessment of dysphagia in children with severe spastic cerebral palsy. Dysphagia 1994; 9: 174179

14. Wolf LS, Glass RG. Feeding and Swallowing Disorders in infancy: assessment and management, 1st ed, Arizona, Therapy Skill Builders, 1992, 85-147

15. Jelm JM. Oral-motor feeding rating scale, 1st ed, Arizona, Therapy Skill Builders, 1990, 1-13

16. Selley WG, Ellis RE, Flack FC, Brooks WA. Coordination of sucking, swallowing and breathing in the newborn: its relationship to infant feeding and normal development. Br J Disord Commun 1990; 25: 311-327

17. Kenny DJ, Koheil RM, Greenberg J, Reid D, Milner M, Moran R, Judd PL. Development of a multidisciplinary feeding profile for children who are dependent feeders. Dysphagia 1989; 4: 16-28

18. Morris, SE, Klein MD. Pre-feeding skills: a comprehensive resource for feeding development, 2 nd ed, San Antonio, Therapy Skill Builders, 2000, 72-89

19. Braun MA, Palmer MM. A pilot study of oral-motor dysfunction in "at-risk" infants. Phys Occup Ther Pediatr 1985; 5: 13-26 
Appendix 1. SOMA OMC Category: Puree

\begin{tabular}{|c|c|c|}
\hline & & No \\
\hline React & Head orientation to spoon & \\
\hline Sequenc & Smooth rhythmic sequence & \\
\hline Lip & $\begin{array}{l}\text { Lower lip draws inwards around } \\
\text { spoon }\end{array}$ & \\
\hline Lip & Upper lip removes food from spoon & \\
\hline Lip & Lower/upper lip assists in cleaning & \\
\hline Lip & $\begin{array}{l}\text { Lower lip active during suck/ } \\
\text { munch/chew }\end{array}$ & \\
\hline Tongue & Consistent/considerable protrusion & \\
\hline Tongue & Protrusion beyond incisors & \\
\hline Jaw & Graded jaw opening & \\
\hline Sum of $s$ & raded boxes & \\
\hline Cutting s & $\begin{aligned} \text { core: } & \geq 3 \text { indicates oral motor } \\
& \text { dysfunction }\end{aligned}$ & \\
\hline & $<3$ normal oral motor function & \\
\hline
\end{tabular}

Appedix 2. SOMA OMC Category: Semi-solid

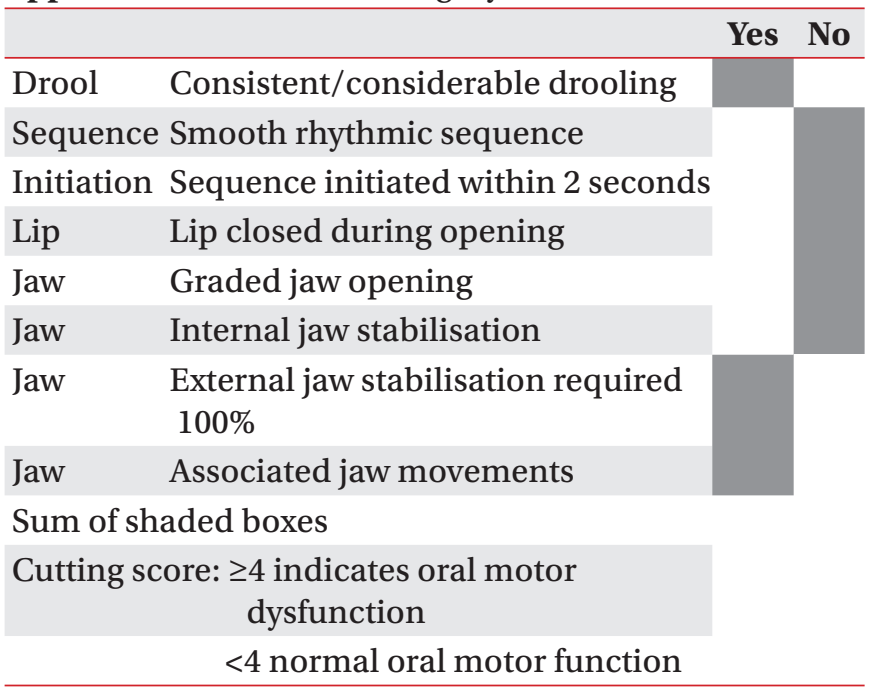

Appedix 3. SOMA OMC Category: Solid

\begin{tabular}{|c|c|c|}
\hline \multicolumn{3}{|c|}{ Yes } \\
\hline Food loss & None/trivial & \\
\hline Drool & Consistent/considerable drooling & \\
\hline \multicolumn{2}{|c|}{ Sequence Smooth rhythmic sequence } & \\
\hline Lip & $\begin{array}{l}\text { Lower lip draws inwards around } \\
\text { spoon }\end{array}$ & \\
\hline Lip & Upper lip removes food from spoon & \\
\hline Lip & $\begin{array}{l}\text { Lower lip behind upper teeth/ } \\
\text { sucking }\end{array}$ & \\
\hline Lip & $\begin{array}{l}\text { Lower lip active during suck/ } \\
\text { munch/chew }\end{array}$ & \\
\hline Tongue & $\begin{array}{l}\text { Transient/minimal tongue } \\
\text { protrusion }\end{array}$ & \\
\hline Jaw & Graded jaw opening & \\
\hline \multicolumn{2}{|c|}{ Sum of shaded boxes } & \\
\hline \multicolumn{2}{|c|}{$\begin{aligned} \text { Cutting score: } & \geq 4 \text { indicates oral motor } \\
& \text { dysfunction }\end{aligned}$} & \\
\hline & $<4$ normal oral motor function & \\
\hline
\end{tabular}


Appedix 4. SOMA OMC Category: Cracker

\begin{tabular}{|c|c|c|}
\hline & & Yes No \\
\hline Food loss & Profuse/marked food loss & \\
\hline Drool & Profuse/marked drooling & \\
\hline Initiation & Sequence initiated within 2 seconds & \\
\hline Lip & $\begin{array}{l}\text { Lower lip behind upper teeth to } \\
\text { suck }\end{array}$ & \\
\hline Lip & $\begin{array}{l}\text { Lips close around stimulus during } \\
\text { bite }\end{array}$ & \\
\hline Lip & $\begin{array}{l}\text { Lips close intermittently during } \\
\text { suck/munch/chew }\end{array}$ & \\
\hline Tongue & $\begin{array}{l}\text { Transient } / \text { minimal tongue } \\
\text { protrusion }\end{array}$ & \\
\hline Tongue & $\begin{array}{l}\text { Considerable/consistent tongue } \\
\text { protrusion }\end{array}$ & \\
\hline Tongue & Protrusion beyond incisors & \\
\hline Tongue & Protrusion beyond lips & \\
\hline Jaw & $\begin{array}{l}\text { Internal jaw stabilisation } \\
\text { established }\end{array}$ & \\
\hline Jaw & $\begin{array}{l}\text { Variable stabilisation (not fully } \\
\text { estabilished) }\end{array}$ & \\
\hline Jaw & External stabilisation & \\
\hline Jaw & Vertical movements & \\
\hline Jaw & Wide vertial excursions & \\
\hline Jaw & Small vertial excursions & \\
\hline Jaw & Associated head movements to bite & \\
\hline Jaw & Uses fingers to transfer food & \\
\hline Swallow & Gagging & \\
\hline Bite & Controlled sustained bite & \\
\hline Bite & Graded jaw opening & \\
\hline Bite & Mouths cracker only & \\
\hline \multicolumn{2}{|c|}{ Sum of shaded boxes } & \\
\hline \multicolumn{2}{|c|}{$\begin{aligned} \text { Cutting score: } & \geq 9 \text { indicates oral motor } \\
& \text { dysfunction }\end{aligned}$} & \\
\hline & $<9$ normal oral motor function & \\
\hline
\end{tabular}

Appedix 5. SOMA OMC Category: Liquid-bottle

\begin{tabular}{|c|c|c|}
\hline & & Yes \\
\hline React & Anticipatory mouth opening & \\
\hline React & No liquid enters mouth & \\
\hline Accept & Accepts liquid within 2 seconds & \\
\hline Lip & Upper lip firmly seals around teat & \\
\hline Lip & $\begin{array}{l}\text { Intermittent/incomplete upper lip } \\
\text { contact/seal }\end{array}$ & \\
\hline Lip & $\begin{array}{l}\text { Intermittent/incomplete lower lip } \\
\text { contact/seal }\end{array}$ & \\
\hline Lip & Lip closure during swallow & \\
\hline Jaw & Small vertical movements & \\
\hline Sequence & Smooth rhythmic sequence & \\
\hline \multicolumn{2}{|c|}{ Sum of shaded boxes } & \\
\hline \multicolumn{2}{|c|}{$\begin{aligned} \text { Cutting score: } & \geq 5 \text { indicates oral motor } \\
& \text { dysfunction }\end{aligned}$} & \\
\hline & $<5$ normal oral motor function & \\
\hline
\end{tabular}

Appedix 6. SOMA OMC Category: Liquid-cup

\begin{tabular}{|c|c|}
\hline \multicolumn{2}{|c|}{ Yes } \\
\hline Accept & Accepts within 2 seconds \\
\hline Sequencing & $\begin{array}{l}\text { Panic reactions when liquid } \\
\text { placed in mouth }\end{array}$ \\
\hline Sequencing & Choking \\
\hline Liquid loss & Profuse/marked liquid loss \\
\hline Tongue & Tongue thrust \\
\hline Tongue & Asymmetry \\
\hline Jaw & Small vertical movements \\
\hline Jaw & Jaw clenching \\
\hline Swallow & Gagging \\
\hline \multicolumn{2}{|c|}{ Sum of shaded boxes } \\
\hline \multicolumn{2}{|c|}{$\begin{aligned} \text { Cutting score: } & \geq 5 \text { indicates oral motor } \\
& \text { dysfunction }\end{aligned}$} \\
\hline & $<5$ normal oral motor function \\
\hline
\end{tabular}

